\title{
A Review of Recycling Status of Decommissioned Lithium Batteries
}

\author{
Yaodong Chen, Aichun Dou * and Ye Zhang \\ School of Materials Science and Engineering, Jiangsu University, Zhenjiang, China
}

This review analyzes the current global use of lithium batteries and the recycling of decommissioned lithium batteries, focusing on the recycling process, and introduces the status of domestic and foreign recycling industry of decommissioned lithium batteries. It also points out the existing problems and the prospects for the future development of the decommissioned lithium batteries recycling in China.

Keywords: decommissioned lithium batteries, valuable metal, metallurgical process, recovery, status

\section{INTRODUCTION}

With the development of scientific level and the continuous progress of human society, mobile phones, computers, electric vehicles have become essential daily necessities, and the problems of energy depletion and environmental pollution are becoming increasingly prominent. According to statistics, the global production of lithium batteries has increased significantly since 2014. At present, China's total productions of the lithium batteries has leapt to the first in the world. According to the

Edited by: Dang Feng,

Shandong University, China

Reviewed by:

Xuheng Liu,

Central South University, China Weifeng Liu,

Central South University, China

Jialiang Zhang,

University of Science and Technology Beijing, China

${ }^{*}$ Correspondence:

Aichun Dou

aichund@163.com

Specialty section: This article was submitted to

Energy Materials,

a section of the journal

Frontiers in Materials

Received: 28 November 2020

Accepted: 08 January 2021

Published: 30 April 2021

Citation:

Chen Y, Dou A and Zhang Y (2021) A

Review of Recycling Status of

Decommissioned Lithium Batteries.

Front. Mater. 8:634667.

doi: $10.3389 /$ fmats.2021.634667 statistics, the service life of lithium battery in an automobile is about 3-8 years (Contestabile et al., 2001; Ma et al., 2013). Therefore, China will enter the situation of large-scale power battery decommissioning by 2020. It is estimated that the number of decommissioned lithium batteries will be close to 240 thousand tons, and the number will reach 1.16 million tons by 2023 , the data here is shown in Figure 1 (Heping, 2019).

The Lithium battery is mainly composed of five parts: positive electrode, diaphragm, negative electrode, electrolyte and battery shell. The positive electrode is usually lithium cobalt oxide, lithium iron phosphate and other materials, which are fixed on the electrode with PVDF during preparation; the negative electrode is traditionally covered with graphite carbon materials in a particular balance on the copper foil. Generally, the proportion of Cobalt content in decommissioned lithium batteries is about $5-15 \%$, the percentage of Lithium content is almost $2-7 \%$, and the Nickel content makes up 0.5-2\% (Jouliem et al., 2014). If these valuable metals could be recycled reasonably, it can not only avoid the severe environmental pollution and waste of resources and energy caused by decommissioned lithium batteries, but also alleviate the lack of lithium cobalt nickel resources in China, which is an effective way to solve the current resource shortage.

\section{RECYCLE PROCESS}

At present, there are many kinds of recycling methods for decommissioned lithium batteries, still components of batteries produced by different manufacturers are not the same, so the valuable details recovered are also various. Under the influence of economic orientation, the primary recovery methods are focused on the recovery of practical metal elements such as Li, Co, Ni, Mn, etc. (Wang et al., 2019). In industry, after the pre-treatment (discharge, disassembly and separation) of decommissioned lithium batteries, it is not easy to separate the cathode materials due to their adhesion with PVDF. Therefore, the valuable parts are separated and enriched by dissolving in 
N,N-Dimethylformamide or thermal decomposition at high temperature, which improves the recovery efficiency.

The recovery processes of decommissioned lithium batteries are mainly divided into physicochemical method, pyrometallurgy, hydrometallurgy and new biotechnology.

The physicochemical method is to use the physicochemical reaction process to recycle the decommissioned lithium batteries. The main techniques include a mechanical grinding method and flotation method. Mechanical grinding is a method that uses heat generated by mechanical grinding to make electrode materials react with abrasive materials and convert lithium compounds into salts. The principle of flotation method is to separate and recover metal compound powder by using the difference of hydrophilicity of material surface. The advantages of flotation are low cost, low energy consumption and no secondary pollution, so it has a good application prospect (Tao, 2015).

Pyrometallurgy is to remove organic materials such as $\mathrm{C}$ and PVDF from electrode materials by high-temperature incineration, at the same time, the metal and its compounds in decommissioned lithium batteries will undergo redox reaction, and then the metal compounds will be recovered in the form of condensation. Pyrometallurgical process usually has better costeffectiveness, easy to realize industrial application and high recovery efficiency. For example, Umicore has developed a coking process that treats decommissioned lithium batteries as natural ore (Meshram et al., 2014). The decommissioned lithium batteries are directly put into the melting furnace without pretreatment. During the heating process, the plastics, organic solvents and graphite in the battery provide heat during the combustion process, while the metal components are reduced and converted into alloys. This process can avoid the problem of safety risk in the process of battery disintegration and crush. At the same time, high-temperature smelting not only comprehensively recovers valuable metals such as cobalt, nickel, manganese and copper, but also uses plastics and graphite carbon to produce clean and harmless slag. The process is simple, and the recovered $\mathrm{Ni}$ can be obtained high purity compounds can be directly returned to battery material production to realize metal recycling. However, pyrometallurgical process also has serious shortcomings, such as high energy consumption, hazardous gas treatment problems generated in the incineration process, which are not conducive to its largescale production.

Compared with other recovery technologies, hydrometallurgy technology is more widely used because of its high recovery rate and high product purity. In the process of dissolving decommissioned lithium batteries, the valuable elements in the spent batteries are leached in the leach solution with organic or inorganic acids. Then the free $\mathrm{Li}, \mathrm{Co}, \mathrm{Ni}$ in the leaching solution are extracted in the form of oxides and salts by metal separation and extraction process. Taking Fortum company as an example, the recovery rate of decommissioned lithium batteries reached more than $80 \%$ by adopting low carbon dioxide hydrometallurgy recovery method. Hydrometallurgy process is simple; equipment requirements are not high, suitable for large-scale production, is one of the most widely used recovery technology in the world, the flowchart is shown in Figure 2. However, the hydrometallurgical process is complex, different electrode materials have a great influence on the leaching rate, and the waste liquid generated by the treatment still needs to be treated.

New biotechnology is a new scientific research project at home and abroad in recent years, which can better avoid the problems of high energy consumption and high pollution in the traditional technology. Microbial metabolism is used to produce a variety of organic acids, adjust the solution environment and dissolve metal ions. It is found that a combination of organic acids, such as gluconic acid, citric acid and oxalic acid, can be produced by culturing the corresponding strains and utilizing the respiration and metabolism of the bacteria, which has a good leaching effect on the metals in the decommissioned batteries (Shouping et al., 2017). Cerruti et al. (1998) used Thiobacillus ferrooxidans to dissolve and leach decommissioned nickel-cadmium batteries, and the recovery rates of cadmium, nickel and iron in the storms were high, indicating that Bioleaching Technology is ideal in the recovery of spent and decommissioned nickel-cadmium batteries. However, at present, due to the high requirements of microbial culture conditions and the low leaching rate compared with an organic or inorganic acids in traditional industries, the new biotechnological method is still in the laboratory research stage and has not been industrialized.

\section{PRESENT SITUATION}

For now, the recycling technology of decommissioned lithium batteries of foreign enterprises is relatively mature.

AEA company crushed the decommissioned lithium batteries at low temperature, separated them, added acetonitrile as organic solvent to extract electrolyte, and then used N-methyl pyrrolidone (NMP) as solvent to extract adhesive (PVDF). $\mathrm{Cu}, \mathrm{Al}$ and plastics were screened and the product was CoO (Vadenbo, 2009).

Umicore company recovered batteries materials are made into $\mathrm{Co}(\mathrm{OH})_{2}$ and $\mathrm{Ni}(\mathrm{OH})_{2}$ through its own special furnace. A large amount of heat released by the combustion of graphite and organic solvent provides energy for the reaction. Valuable metal ions are recovered by wet method. $\mathrm{LiCoO}_{2}$ is prepared by $\mathrm{CoCl}_{2}$ and sold as electrode material (Hageluken et al., 2005).

ToxCO (Kang et al., 2010) company processes decommissioned lithium batteries at reduced temperatures and

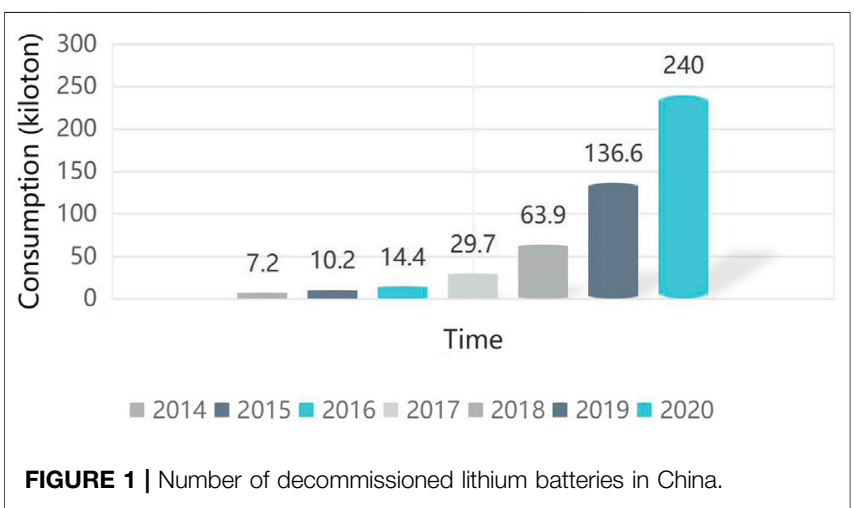




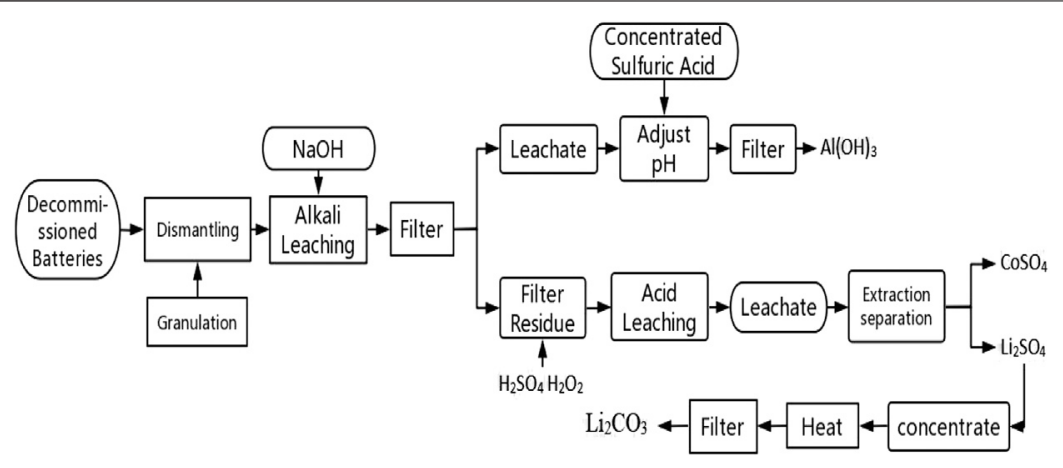

FIGURE 2 | Flow chart of lithium battery recovery in hydrometallurgy industry.

then adds the solid $\mathrm{NaOH}$. At this time, metal $\mathrm{Li}$ is converted into $\mathrm{LiOH}$, and $\mathrm{CO}_{3}{ }^{2-}$ is added to make $\mathrm{LiOH}$ react to form $\mathrm{Li}_{2} \mathrm{CO}_{3}$. After ball mill method and washing, the electrode materials such as $\mathrm{LiCoO}_{2}$ and $\mathrm{Li}_{2} \mathrm{CO}_{3}$ were separated from the raw materials. The $\mathrm{LiFePO}_{4}$ electrode materials after low-temperature treatment had a larger capacity. Low-temperature ball mill method can reduce the cost of enterprises, and because of its simple process and low pollution to the environment, it is also widely used in the recovery process.

Recupyl company's recycling process of decommissioned lithium batteries is carried out under the protection of inert gas mixture. The decommissioned lithium batteries are crushed and separated by magnetic separation to obtain the valuable metals needed. Some metal ions were leached with $\mathrm{LiOH}$ solution, and then insoluble metal ions were leached with strong acid. The precipitates of other metals were obtained by adding $\mathrm{Na}_{2} \mathrm{CO}_{3}$. After filtration, the filtrate solution was oxidized by adding $\mathrm{NaClO}$ to obtain $\mathrm{CO}(\mathrm{OH})_{3}$ precipitation. Taking $\mathrm{CO}_{2}$ into inert gas was introduced into the solution containing $\mathrm{Li}$ to obtain $\mathrm{Li}_{2} \mathrm{CO}_{3}$ precipitation.

China's lithium battery recycling industry is in its infancy (Lingjun et al., 2020; Yihan et al., 2020; Zengsheng et al., 2021), and there are not many enterprises that meet the standard conditions. Encouraged by the rise of new energy industry and country's policies, many battery companies are engaged in the recycling of decommissioned lithium batteries. Such as: Oriental Seiko, BYDCo, Contemporary Amperex Technology Co and other enterprises are making contributions to the sustainable development of the country.

There are some problems in the development of the decommissioned lithium batteries recycling industry in China:

1. Although the market prospect of decommissioned lithium batteries recycling industry is broad, it is still in the initial stage, and the system of each link is not mature;

2. It is the lack of recycling technology. Most of the critical technology patents are in the hands of foreign enterprises, and the recovery process and technical means of decommissioned lithium batteries need to be broken through, and the discharge and storage of decommissioned lithium batteries are lack of standards;
3. Lack of incentive policy measures to protect. Affected by technology and scale, the recovery of valuable metals in the market is not high, and the economy is low. The relevant fiscal and tax incentive policies are not perfect, and the marketoriented recycling mechanism has not yet been established.

\section{CONCLUSION}

The recovery of decommissioned lithium batteries is mainly based on hydrometallurgical technology with high extraction efficiency and mature method, which is conducive to industrialization.

At present, the development of lithium battery is in the gap of change. With the evolution and development of lithium battery materials, the recycling of decommissioned lithium batteries will inevitably usher in new opportunities and challenges. There is still a particular gap between China's decommissioned lithium battery recycling technology and foreign enterprises. In the future, the electrode materials of lithium batteries will change, and the recovery process will be more complicated. Only by innovating and refining new recovery methods can we meet the demand of future decommissioned lithium batteries and improve the coordination between efficiency and cost. Research institutions and enterprises should strive to optimize the recycling process, further promote various new technologies to realize industrial application, to make the recycling of decommissioned lithium batteries develop towards the direction of low cost, comprehensive, diversified and green.

\section{AUTHOR CONTRIBUTIONS}

YC mainly responsible for the writing of the review. $\mathrm{AD}$ is advisor and corresponding author.

\section{ACKNOWLEDGMENTS}

This review was financially supported by the National Natural Science Foundation of China (No. 51604124). 


\section{REFERENCES}

Cerruti, C., Curutchet, G., and Donati, E. (1998). Bio-dissolution of spent nickelcadmium batteries using Thiobacillus ferrooxidans. J. Biotechnol. 62, 209-219. doi:10.1016/s0168-1656(98)00065-0

Contestabile, M., Panero, S., and Scrosati, B. (2001). A laboratory-scale lithium-ion battery recycling process. J. Power Sources 92 (1), 65-69. doi:10.1016/s03787753(00)00523-1

Hageluken, C., Refining, U. P. M., and Greinerstraat, A. (2005). "Recycling of electronic scrap at Umicore's integrated metals smelter and refinery" in Proceedings of EMC, 307-323.

Heping, Z. (2019). The market value is more than 30 billion yuan, and the "money" of waste battery recycling is optimistic. Petrochemicals 6, 28. doi:10.1007/F978981-13-9173-6

Joulié, M., Laucournet, R., and Billy, E. (2014). Hydrometallurgical process for the recovery of high value metals from spent lithium nickel cobalt aluminum oxide based lithium-ion batteries. J. Power Sources 247 (3), 551-555. doi:10.1016/j. jpowsour.2013.08.128

Kang, J., Senanayake, G., Sohn, J., and Shin, S. M. (2010). Recovery of cobalt sulfate from spent lithium ion batteries by reductive leaching and solvent extraction with Cyanex 272. Hydrometallurgy. 100 (3), 168-171. doi:10.1016/j.hydromet.2009.10.010

Li, L., Xia, L., Yang, H., Zhan, X., Chen, J., Chen, Z., et al. (2020). Solid-state synthesis of lanthanum-based oxides Co-coated LiNi0.5Co0.2Mn0.3O2 for advanced lithium ion batteries. J. Alloys Compd. 832, 154959. doi:10.1016/j. jallcom.2020.154959

Ma, L., Feng, T., and Jiao, Q. (2013). Beryllium aluminum interface structure of powder metallurgy beryllium aluminum alloy. Hot Work. Process. 42 (4), 100-102. doi:10.31399/asm.hb.v07.9781627081757

Meshram, P., Pandey, B. D., and Mankhand, T. R. (2014). Extraction of lithium from primary and secondary sources by pre-treatment, leaching and separation: a comprehensive review. Hydrometallurgy 150, 192-208. doi:10.1016/j. hydromet.2014.10.012

Shouping, W., Jie, S., and Tian, Z. (2017). Research progress of metal material recycling technology in waste lithium-ion batteries. Energy Storage Sci. Technol. 6 (6), 1196-1207. doi:10.3390/ma13030801

Tao, Z. (2015). Mechanical crushing of spent lithium-ion batteries and flotation of cobalt enriched crushed products. Xuzhou: China University of Mining and Technology.

Vadenbo, C. O. (2009). Prospective environmental assessment of lithium recovery in battery recycling $[E B / O L]$.

Wang, H., Huang, Y., Huang, C., Wang, X., Wang, K., Chen, H., et al. (2019). Reclaiming graphite from spent lithium ion batteries ecologically and economically. Electrochim. Acta 313, 423-431. doi:10.1016/j.electacta.2019. 05.050

Yihan, Z., Dongfeng, W., and Xuehua, Y. (2020). Rational design for $\mathrm{Mn}_{3} \mathrm{O}_{4} @$ carbon foam nanocomposite with 0D@3D structure for boosting electrochemical performance. doi:10.1021/acs.energyfuels.Oc02627

Zengsheng, L., Lingjun, L., Jie, C., Huiping, Y., Lingfeng, X., Jiaxin, C., et al. (2021). Effects of chelating agents on electrochemical properties of $\mathrm{Na}_{0.9} \mathrm{Ni}_{0.45} \mathrm{Mn}_{0.55} \mathrm{O}_{2}$ cathode materials. J. Alloys Compd. 855, 157485.

Conflict of Interest: The authors declare that the research was conducted in the absence of any commercial or financial relationships that could be construed as a potential conflict of interest.

Copyright (c) 2021 Chen, Dou and Zhang. This is an open-access article distributed under the terms of the Creative Commons Attribution License (CC BY). The use, distribution or reproduction in other forums is permitted, provided the original author(s) and the copyright owner(s) are credited and that the original publication in this journal is cited, in accordance with accepted academic practice. No use, distribution or reproduction is permitted which does not comply with these terms. 